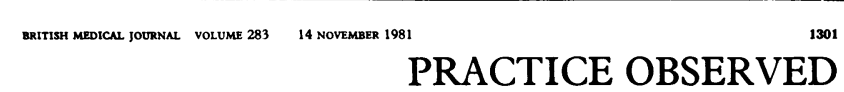

\section{Practice Research}

Treatment of urinary tract infection with a single dose of amoxycillin, co-trimoxazole, or trimethoprim

R B HARBORD, R N GRÜNEBERG

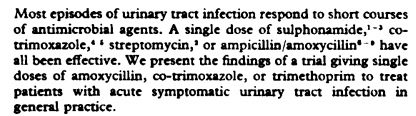

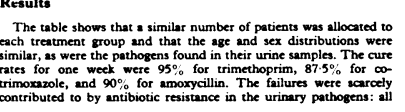

Patients and methods

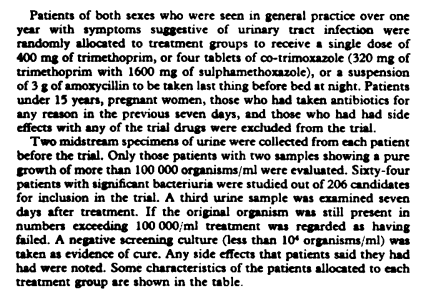

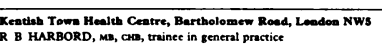
Ualverasty COlleges Hoopital, Loadoes WCIE OAU

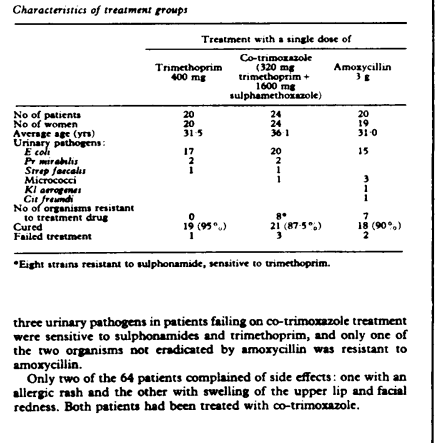

BRITISH MEDICAL JOURNAL VOLUME $283 \quad 14$ NOVEMBER 1981 We are grateful to our colleagues at Kentish Town Health Centre
for tions.

High curc rates were achieved in this trial, with all three
single-dose treatments producing similar results. In most of the singe-dose treasments producing similar results. In most of the
episodes of symptomatic urinary cract infection in general
practice the usual five to seven day course of chemotherapy seems excessive. Patients whose infection is not cleared by
single dose may require fuller investigation and more carefully selected treatment." Some patients were cured with amoxycillin
despite the in vitro amoxycillin-resistance of the pathogen,
presumbsly because of the very high urinary concentrations of the drug after 2 dose of $3 \mathbf{g}$.
Side effects were not $2 \mathrm{z}$ major problem in this or most other

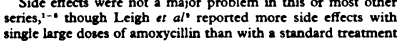

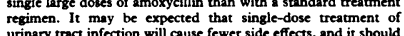

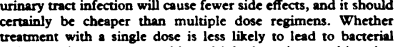
resistance than treand
should be studied.

Conclusione

Sixty-four patients with accute symptomatic urinary tract
infection in general practice were treated with a single dose of

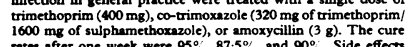
ratere not a problem. Since compliance is likely to be good, cure
rates are high, side effects are uncommon, and costs are low single-dose tre
more widely.

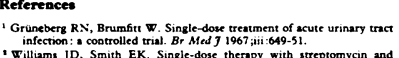

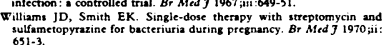

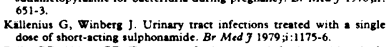

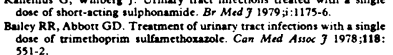

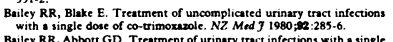

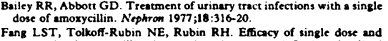

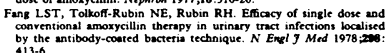

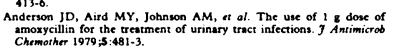

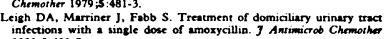

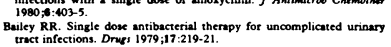 (Accopred 13 October 1981)}

\title{
Treatment of acute urinary tract infection with three
} doses of co-trimoxazole

J RAPOPORT, G A REES, N J WILLMOTT, R C B SLACK, F W O'GRADY

Gould et al' showed that bacteria disappear from infeceded urine
within hours sfter treatment is started. Cartell en al' showed chat
after a single dose of a drug to which the organism was sensitive

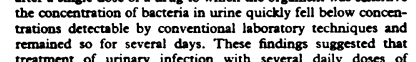
treatment of urinary infection with several daily doses of
antibiotic for a week or more results in ppatients receiving
substiantially more of a drug than is necesssary to climinate the Evidence exists that patients will respond to less treacmen
infection.

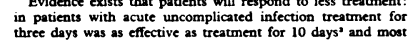

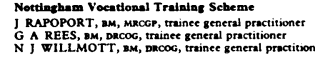

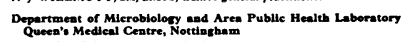

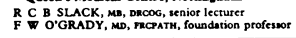

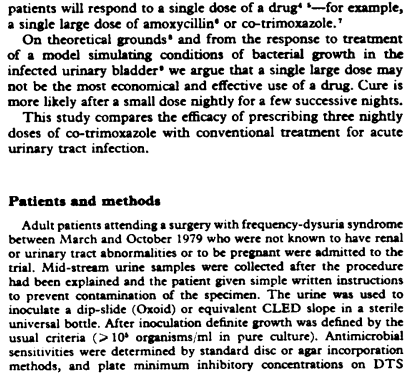

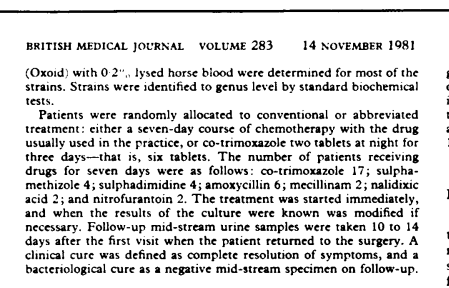

Results

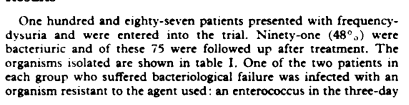

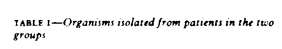

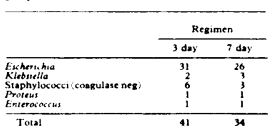

TABLL II-Results of trateatment

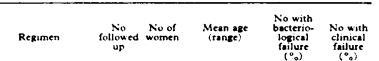

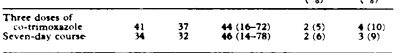

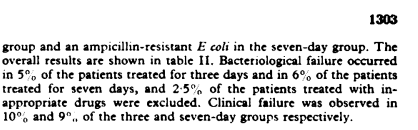
Discussion

Despite the many studies on the treatment of acute urinary
tract infection, the optimum dose or duration of treatment has Iract infection, the optumum dose or duration of treatment has
not been defined. What has emerged clearly is that most patients
seen in general practice will respond to minimal treatment, and failure to respond identifies those who require more intensive
treatment esp possibly investigation. The precise are of abbreviated treatment appears to be unimportann. The results
of 10 -day or three-day courses with single large three-nightly allowed to play a part, and some may welcome treatment with
single dose; some may prefer to continue treatment for a day or two while symptoms linger. In our sudy a conventional dose of
co-trimoxazole repected on two successive nights (a total of six
tablets) was as effective as conventional treatment (14 or more cablets) was as effective as conventional treatment (14 or more
tablets) in eliminating acute uncomplicated urinary infection in
patients

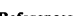

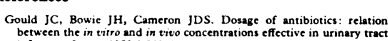

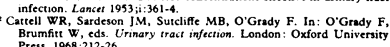

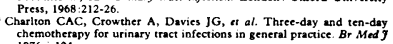

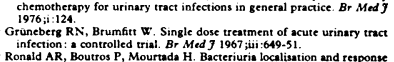

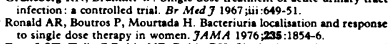

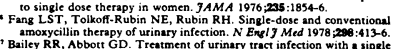

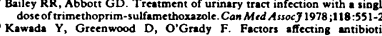

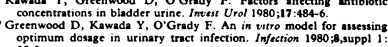
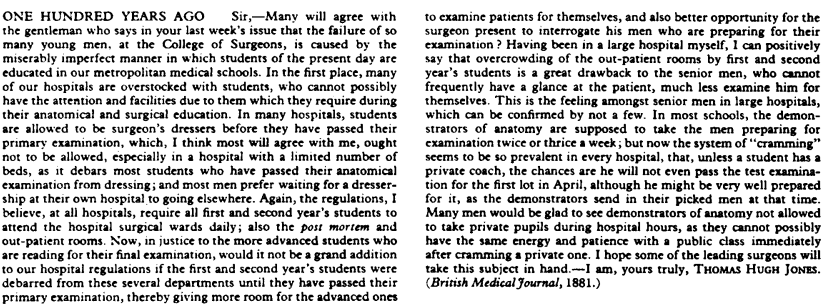

1304

BRITISH MEDICAL JOURNAL VOLUME $283 \quad 14$ NOVEMBRR 1981

\section{Women in General Practice}

C B CHALLACOMBE

About 10 years ago, while still working as a house officer in a
district general hospital, I was fortunate enough to be offered a district general hospital, I was fortunate enough to be offered a
chance to ioin two other doctors, both men, in a busy urban
practice. I had been martied for just over a year and had by then realised the practical difficulties of combining hospital
medicine with the sort of family life that I wanted. It was my
intention to have children and to be able to join my husband, who was working in dental research, in any foreign travel if the
opportunity arose. I could also see the problems of combining these wishes with a full-time partnership in general practice.
Before ioning the practice I discussed these plans with my prospective partners. I told them that it was my husband's
intention to take ssabbatical year abroad at some time. We also discussed the possibility that $m y$ husband might move to a
different hospital, in which case $\mathrm{I}$ might have to leave the practice.
My partners and I decided to have a clause regarding maternity
leave in the partrenership agreement. This stituplated that I I was
allowed three months' maternity leave with a reduced percentage of the practice profits. The maternity allowance from the family
practitioner committee, together with the remaining profiss, would provide the locum's salary while I was away.
I worked for two and a half years in the practice befor Iv worked for two and a half years in the practice before
having my first child. I continued to work fullitime unnit a
month before the baby was due. At the time I Ifet that I could have worked for longer. I would have preferred to decrease $m y$
work load gradually over the last few weeks. But, because $m y$ partners thought that it would be difficult to organise arrangecomplectly and have a full-time locum
There were diffectlus in

three months since, not unnaturally, my partners insisted upon the locum being acceptable to them both. They also felt series of part-time locums, which might have been easier for me to organise. Eventually, with the help of my partners, a
locum was found who met all the requirements. Fortunately my son was only a weck late in arriving, and I
returned to work when he was eight weeks old. The first few months were difficult for me emotionally, since it took some
time to adjust to leaving my baby with someone else while I time to adjust to leaving my baby with someone else while 1 and managed to arrange my surgery hours around feeding times.
I found night duties most taxing but was able to employ a the first few months.
the oulp me dight calls during During my second pregnancy three years later the extra
family commitments that I now had made me realise that family commitments that I now had made me realise that
I would appreciate more than the three months' maternity
leave which had been agreed. After discussions with my parterers an extra month was arranged, which was taken partly as unpaid
leave and partly as two weeks of my annual holiday. Even with practice, but I was under pressure from my partrens to do do so.
The following months were the most stressfula and least en-
joyable of my practice career-so far. It required an enormous London SE10 9HO
C B CHALLACOMBE, MB, as, general practitioner

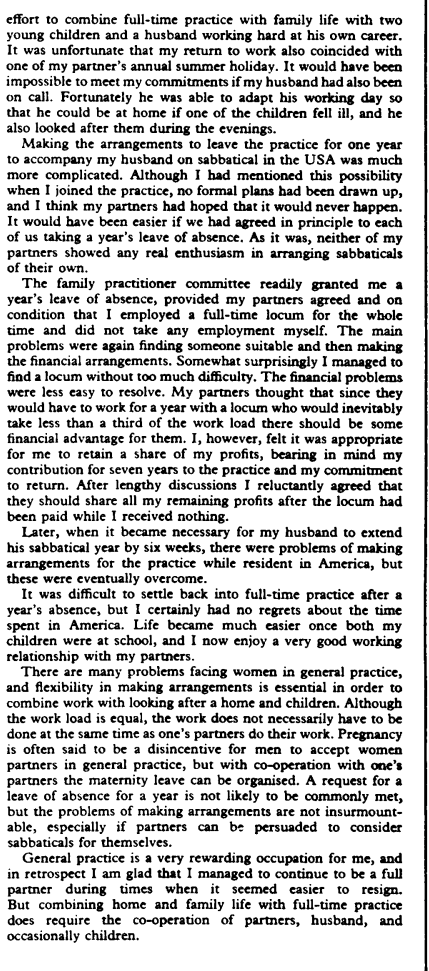

